\title{
Caring for Hospitalized Patients with Diabetes Mellitus, Hyperglycemia, and COVID-19: Bridging the Remaining Knowledge Gaps
}

\author{
Amisha Wallia $^{1,2} \cdot$ Grace Prince $^{1} \cdot$ Emilie Touma $^{2} \cdot$ Malek El Muayed $^{1} \cdot$ Jane Jeffrie Seley $^{3}$
}

Accepted: 26 October 2020 / Published online: 26 November 2020

(C) Springer Science+Business Media, LLC, part of Springer Nature 2020

\begin{abstract}
Purpose of Review This review discusses the interplay between coronavirus disease 2019 (COVID-19, caused by SARS-CoV-2 infection), diabetes mellitus, and hyperglycemia in the hospital setting. There are data emerging about diabetes and hyperglycemia, their prevalence, and potential risks in the setting of SARS-CoV-2 infection and COVID-19.

Recent Findings It is known that viral infections exert effects on beta cell function and insulin resistance. Therefore, much can be learned about SARS-CoV-2/COVID-19 from examining these known relationships. Such pathophysiological underpinnings may unlock greater understanding as we navigate atypical cases of hyperglycemia, severe insulin resistance, and diabetic ketoacidosis amidst COVID-19. Glycemic outcomes likely have beneficial effects on morbidity and mortality, but this needs to be studied.

Summary Changes in diabetes-related protocols and new technology can be deployed in the inpatient setting to potentially improve healthcare worker and patient safety; however, one must weigh the risks and benefits of implementation during a pandemic. Ultimately, knowledge and research must be shared at record speed to combat this global crisis.
\end{abstract}

Keywords Diabetes $\cdot$ Covid-19 $\cdot$ SARS-CoV2 $\cdot$ Inpatient management $\cdot$ Hyperglycemia

\section{Introduction: SARS-CoV-2 Infection, COVID-19, Obesity, and Diabetes Mellitus}

On December 31, 2019, The World Health Organization (WHO) was notified of cases of pneumonia of unknown etiology originating in Wuhan, China. These cases were quickly linked to a novel beta-coronavirus, initially identified as 2019nCoV, now known as SARS-CoV-2 [1]. Less than 3 months later, by March 11, 2020, the WHO declared the coronavirus disease (COVID-19) a pandemic, affecting most if not all countries across the globe [1,2]. As of September 9, 2020, over 27 million cases of COVID-19 have been detected and confirmed, including: the USA with $6,330,316$ cases, Russia with $1,037,526$ cases, the UK with 354,934 cases, Italy with 280,153 cases, and China with 90,087 cases [1], while 898,456 individuals have died [1]. As the crisis has swept

This article is part of the Topical Collection on Hospital Management of Diabetes

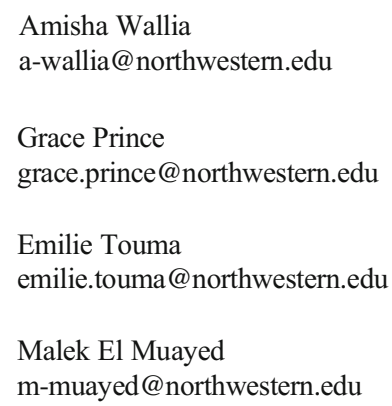

Jane Jeffrie Seley
jas9067@med.cornell.edu

1 Division of Endocrinology, Metabolism and Molecular Medicine, Feinberg School of Medicine, Northwestern University, Chicago, IL, USA

2 Institute of Public Health, Feinberg School of Medicine, Northwestern University, Chicago, IL, USA

3 Division of Endocrinology, Diabetes, and Metabolism, Weill Cornell Medicine, New York, NY, USA 
the globe, over-burdening healthcare systems in the USA and many other countries, there is an urgent need to better understand phenotypic features that portend greater disease severity.

In 2003, the coronavirus SARS-CoV was identified as the pathogen responsible for an outbreak of respiratory disease in China [3]. It is known that both a history of diabetes mellitus (DM) as well as fasting hyperglycemia were associated with increased morbidity and mortality in patients infected with SARS-CoV $[4,5]$. Similarly, data have emerged suggesting patients with DM have a higher risk of severe disease from SARSCoV-2 infection [6, 7••]. Early on, at the epicenter of the pandemic at Jinyintan Hospital in Wuhan, China, a retrospective cohort study of 201 patients with confirmed SARS-CoV-2 identified $10.9 \%$ with comorbid DM [8]. Additionally, the presence of DM was found to be associated with acute respiratory distress syndrome (ARDS) development [HR 2.34 (CI 1.35-4.05, $p=$ 0.002)] [8]. Subsequent data from the World Health Organization (WHO)-China Joint Mission on Coronavirus Disease 2019 suggested the case fatality rate in patients with underlying DM infected with SARS-CoV-2 is as high as 9.2\% [9]. Likewise, Italian data supports this notion that patients with DM are particularly vulnerable to COVID-19. In March 2020, $33.9 \%$ of patients who died from COVID-19 in Italy had comorbid DM [10]. Finally, in the USA, survey data from 14 states representing $10 \%$ of the US population estimates $28.3 \%$ of patients hospitalized with symptoms of SARS-CoV-2 infection have comorbid DM [2]; the presence of DM has been associated with a higher rate of morbidity and mortality [11]. In a cross-sectional single-site study in New York City of 2741 hospitalized patients with SARS-CoV-2 infection, $35.3 \%$ were obese, $52.1 \%$ had any cardiovascular condition, and $22.6 \%$ had DM [12]. Of those admitted to the hospital with COVID-19, both BMI > 40 and diabetes were significantly associated with critical illness [12]. Newer data corroborated the notion that overweight BMI and obesity are independent markers associated with worse outcomes. Studies by Simonnet et al. [13] and Tartof et al. [14] showed a close, quasi linear association between BMI and the risk for requiring mechanical ventilation as well as mortality in the setting of SARS-CoV-2 infection. As cases are amalgamated and data analyzed, the relationship between DM, obesity and relevant risk factors for poor outcomes will be elucidated (see below). With the COVID-19 pandemic driving population health to the forefront, knowledge surrounding the mechanisms by which obesity, hyperglycemia, and DM may alter the host response to the virus has also become increasingly vital.

\section{Hyperglycemia, DM, and COVID-19 in the Hospital Setting}

An early observational, retrospective study of 88 US hospitals (in 10 states across the country) using an electronic glycemic management system examined 1122 patients with laboratory confirmed SARS-CoV-2 infection [15]. The mortality rate was significantly higher (28.8\%), in 184 patients with diabetes. Importantly, this also held true for persons with no preexisting diabetes who presented with significant hyperglycemia (two or more blood glucoses $>180 \mathrm{mg} / \mathrm{dl}$ in $24 \mathrm{~h}$ ), when compared to those without $(6.2 \%, p<0.001)$. Length of stay was significantly longer in those with DM and/or uncontrolled hyperglycemia; a within-group subanalysis of 184 patients (47.8\% with DM, $52.2 \%$ with hyperglycemia) noted that more patients with hyperglycemia (40/96) died compared to those with diabetes $(13 / 88, p<0.001)$ [15]. Similar findings were noted from a 19 hospital study in Hubei province, China, of 7337 cases of COVID-19, with 952 having a previous history of DM; subjects with type $2 \mathrm{DM}$ had a significantly higher inpatient death rate $(7.8 \%$ vs $2.7 \%, p<0.001)$, even following adjustment for age and gender (HR 1.7, 95\% CI $1.29-2.24, p<0.001$ ) [16]. Those with type 2 DM also had significantly greater occurrence of complications such as ARDS, acute heart, and kidney injury, septic shock, and disseminated intravascular coagulation (DIC), even following adjustment for age, gender and severity of COVID-19 [16].

Subsequent studies from France, England, and the USA have confirmed the close association between obesity, age, and male sex with worse COVID-19-related outcomes in those with diabetes $[7 \bullet \bullet, 17,18]$. Hemoglobin A1c was less strongly associated with adverse outcomes, with some studies showing such association $[7 \cdot \bullet]$, while others did not show such an association $[17,18]$. In terms of diabetes-related complications, the CORONADO study showed that microvascular and macrovascular diabetic complications as well as chronic renal insufficiency were independently associated with increased mortality in persons with diabetes hospitalized for SARS-CoV-2 infection [17]. However, Agrawal et al. [18] did not demonstrate similar findings following adjustment. It is possible that the association between higher HbAlc and SARS-CoV-2 complications may be mediated by preexisting DM complications such as chronic renal insufficiency and coronary artery disease, which also have been shown to be associated with SARS-Co-V-2 complications [17]. In addition, both type 1 and type 2 diabetes have been recognized as common comorbid conditions among patients hospitalized with COVID-19 infection and are associated with more severe disease and, therefore, poorer outcomes $[6,7 \bullet \bullet$, 17]. Insulin usage has also been associated with poor prognosis in retrospective analysis $[18,19]$. In addition, fasting blood glucose at admission $(7 \mathrm{mmol} / \mathrm{L}, 126 \mathrm{mg} / \mathrm{dl})$ was an 
independent predictor of 28-day mortality without previous diagnosis of diabetes, signaling that hyperglycemia in and of itself may be predictive [20].

More in-depth research is needed to understand the interaction between risk factors, hyperglycemia, DM, and morbidity and mortality in the context of COVID-19.

\section{Glycemic Case Presentations, Severe Hyperglycemia, Insulin Resistance, and Diabetic Ketoacidosis}

In line with the well-understood physiologic effects the infectious/inflammatory milieu exerts on glucose levels, it is not entirely surprising that patients have presented with hyperglycemic crises in the context of SARS-CoV-2 positivity (or suspected SARS-CoV-2 positivity as is the case with "persons of interest," [POI]). Cases from around the world have included descriptions of hyperglycemic crisis, severe insulin resistance, and diabetic ketoacidosis [21-23]. In an article in the Lancet from authors with experience across several continents, two types of presentations were noted: severe cases of diabetic ketoacidosis (DKA) at the time of hospital admission, and extreme insulin requirements in those with severe infection [24]. A recent systematic review also noted DKA presentation with high COVID-19 morbidity, with up to $77 \%$ having preexisting type $2 \mathrm{DM}$ and $10 \%$ with new diagnosis of DM [25]. Severe insulin resistance has also been observed during the proinflammatory metabolic state [26]. The interplay between possible insulinopenia and/or insulin resistance and COVID-19 disease and its progression is noted to be an area for further examination.

\section{Understanding Severe Insulin Resistance and DKA}

Hyperglycemia in those without DM, as well as in persons with preexisting DM (type 1 and type 2), is commonly observed in hospitalized patients. This is especially true during conditions that precipitate a state of inflammation, including viral infections. Severe critical illness, steroids, elevated levels of inflammatory cytokines, enteral feeding, and vasopressors are all known to cause insulin resistance in the hospital setting. Several experimental and observational studies suggest that this may be a result of increased insulin resistance as well as suppressed insulin secretion from beta cells [27]. Extreme insulin resistance (defined as $>3$ units/kg/day) [28] has been previously described, albeit rarely, in the hospital setting [29-32].

Complicating the clinical picture of hyperglycemia in the setting of COVID-19 is the fact that therapies administered during the course of the illness such as catecholamines, corticosteroids, hydroxychloroquine, as well as various immunomodulators, may alter glycemic outcomes and need to be taken into account [33-35]. It has been reported that COVID-19, at least in its more severe clinical course, represents a state of increased inflammation. Whether COVID-19 infection induces hyperglycemia via additional mechanisms, beyond the effect of this generalized inflammatory state remains unknown.

Reports of an increased incidence of DKA in persons with COVID-19 may point towards an exaggerated impairment of beta cell insulin secretion. This could conceivably occur through a reversible direct toxic effect on beta cells whether via high levels of inflammatory cytokines or through a yet unknown mechanism. Although triggering of autoimmune beta cell destruction in type 1 diabetes has been postulated by some to be induced through autoimmune mimicry by viral infections [27, 36-40], this may be an unlikely underlying mechanism in COVID-19-related DKA, given that several patients without preexisting type $1 \mathrm{DM}$ perhaps recover without continued need for insulin administration, and the time course does not seem consistent with autoimmune induced beta cell dysfunction. The possibility of a pathogenesis similar to that of ketosis-prone type $2 \mathrm{DM}$ could be considered [41, 42]. Also, more studies are needed to investigate whether SARS-CoV-2 has the capacity to directly infect islet cells as has been postulated for SARS and SARS-CoV-2 [43, 44]. This is plausible by virtue of islets having been shown to express ACE-2 [43, 45]. Expression of TMPRSS2 mRNA in mouse islets has been observed by us (El Muayed research group, unpublished data). Both ACE-2 and TMPRSS2 are thought to be necessary for viral infection [46]. Viremia and infection of nonrespiratory tract organs have been shown to occur in a subset of patients with a more severe SARS-CoV-2 course $[47,48]$. Complicating the clinical picture of SARSCoV-2-related hyperglycemia is the fact that therapies administered during the course of the illness such as catecholamines, corticosteroids, (hyperglycemic effects), various immunomodulators (mixed effects), and hydroxychloroquine (hypoglycemic) may be additional contributors towards altered glycemic outcomes that need to be taken into account [33-35].

It is worth noting that viral infections have been postulated as playing a role in initiating or accelerating the autoimmune process of type $1 \mathrm{DM}$. Indeed, several experimental and human population studies support the hypothesis of an association between infection with viral pathogens, including Coxsackievirus B, rubella, mumps, Rotavirus, Cytomegalovirus, and various Enteroviruses, and the onset of type $1 \mathrm{DM}$ in genetically susceptible individuals. However, a true causal relationship remains a matter of active debate [27, 36-40]. Hypothesized mechanisms include molecular mimicry as well as direct infection of beta cells; these proposed processes are not necessarily mutually exclusive. It has also been reported that Hepatitis C Virus (HCV) antibodies in persons with chronic $\mathrm{HCV}$ infection may contribute to 
an autoimmune-like destruction of beta cells [49]. Table 1 reviews physiologic concepts of interest and possible testing strategies related to atypical case presentations of DM/ hyperglycemia in those with or suspected to have SARS$\mathrm{CoV}-2$. It has to be cautioned that the antibodies commonly associated with type $1 \mathrm{DM}$ may not be a reliable indicator of an autoimmune destruction of beta cells. This is illustrated by the well-recognized entity of autoimmune DM associated with the administration of immune checkpoint inhibitors in patients treated for various neoplasms, where these antibodies are often undetectable [50].

In those patients with atypical DM presentations, who were unable to be tested or had negative SARS-CoV-2 polymerase chain reaction (PCR) based tests, it may be worth setting up serologic (antibody) testing to evaluate if previous infection with SARS-CoV-2 occurred. PCR-based assays to date have shown a sensitivity that is less than optimal. This is thought to be in part due to variable viral load in the nasopharynx, the most common sampling site [51,52]. This may also hamper future antigen-based assays. Validated serological tests with reliable performance hold promise to facilitate better retrospective correlation of clinical courses with past infection $[53,54]$. This testing could be considered in atypical DM/ hyperglycemia case presentations where symptoms of COVID-19 were suspected but original PCR testing was negative or was unable to be done.

\section{Glycemic Goals and Therapeutic Options}

At the present time, there is minimal randomized controlled trial (RCT) evidence in patients who are infected with SARS-
CoV-2 or have COVID-19 in the hospital setting to help inform best glycemic targets or goals. A retrospective report utilizing propensity score matching (1:1), in patients with type 2 DM from Hubei Province, China, noted decreased mortality in those with on-target glucose levels (glycemic variability within $70-180 \mathrm{mg} / \mathrm{dl}[3.9-10 \mathrm{mmol} / \mathrm{L}]$, median glucose $6.4 \mathrm{mmol}, \mathrm{HbA} 1 \mathrm{c} 7.3 \%$ ) than those with above target glucose levels (upper limit of glycemic variability exceeding $180 \mathrm{mg}$ / dl [10 mmol/L, median glucose $10.9 \mathrm{mmol} / \mathrm{L}, \mathrm{HbAlc} 8.1 \%]$ ) (HR $0.13,95 \%$ CI $0.04-0.44, p<0.001$, following adjustment for age, gender, severity of COVID-19 comorbidities, and site effect) [16]. Patients with hyperglycemia and patients with diabetes also had a significant risk of severe disease as compared to those with diabetes and with normoglycemia [55]. Those who were well managed also developed less ARDS, acute heart and kidney injury, septic shock, and DIC [16]. General inpatient glycemic management guidelines should therefore be considered appropriate in keeping with current American Diabetes Association inpatient guidelines; insulin therapy should be initiated for those $>180 \mathrm{mg} / \mathrm{dl}$ $(10 \mathrm{mmol} / \mathrm{L})$ and a target glycemic goal of $140-180 \mathrm{mg} / \mathrm{dl}$ $(7.8-10 \mathrm{mmol} / \mathrm{L})$ is recommended for most patients, with more stringent goals of $110-140 \mathrm{mg} / \mathrm{dl}(6.1-7.8 \mathrm{mmol} / \mathrm{L})$ for select patients if this can occur without hypoglycemia [56].

Both intensive and moderate insulin therapies have been shown to reduce morbidity in multiple patient populations in the hospital setting $[57,58]$. Insulin has been the preferred agent in the hospital setting based on a plethora of RCT data along with years of proven efficacy in the clinical setting and known safety profile [59]. Mechanisms by which insulin therapy improves outcomes in the inpatient setting have been hypothesized to include protection of endothelium, perhaps

Table 1 Potential areas of investigation related to DM and COVID-19 infection

\begin{tabular}{|c|c|}
\hline Investigative area of interest & Studies/therapies for further evaluation \\
\hline $\begin{array}{l}\text { Confirmation of SARS-CoV-2 } \\
\text { diagnosis }\end{array}$ & PCR or other acute tests (antigen once available) during the acute phase, antibody testing postrecovery [102] \\
\hline Insulin resistance & $\begin{array}{l}\text { Plasma level of human insulin and insulin analogue, response to exogenous insulin, calculated HOMA-IR, } \\
\text { c-peptide }\end{array}$ \\
\hline Diabetic ketoacidosis & Beta hydroxybutyrate, acetone, acetoacetate \\
\hline Inflammation & CRP, cytokines, acute phase reactants, triglycerides, free fatty acids $[33,103-106]$ \\
\hline $\begin{array}{l}\text { Therapies altering insulin } \\
\text { resistance/sensitivity }\end{array}$ & $\begin{array}{l}\text { Hydroxychloroquine/chloroquine, azithromycin, remdesivir, DPPIV Inhibitors, ACE-inhibitors/ARBs, } \\
\text { catecholamines, corticosteroids, immune modulators (i.e., sarilumab and others) [33-35, 65, 66, 107] }\end{array}$ \\
\hline $\begin{array}{l}\text { Beta cell function (all disease } \\
\text { phases) }\end{array}$ & C-peptide and plasma glucose (acute and recovery phase) \\
\hline $\begin{array}{l}\text { Autoimmune diabetes (all disease } \\
\text { phases) }\end{array}$ & $\begin{array}{l}\text { Glutamic acid decarboxylase antibodies (GAD-65), Islet cell antibodies, tyrosine phosphatase antibodies (IA-2), } \\
\text { ZnT8 antibodies (acute and recovery phase) [108] genotyping for T1DM associated HLA genotypes [109, 110], }\end{array}$ \\
\hline Beta cell injury* & Beta cell specific cell free DNA, or differentially methylated INS DNA [111-113] \\
\hline $\begin{array}{l}\text { Genetic modulators of glycemic } \\
\text { response** }\end{array}$ & $\begin{array}{l}\text { Genotyping for known T2DM predisposing SNPs and monogenic diabetes [114], whole-genome sequencing or } \\
\text { SNP Array }\end{array}$ \\
\hline
\end{tabular}

*Occurring via direct islet infection facilitated by islet ACE-2/TMPRSS2 or inflammatory destruction

**Including monogenic diabetes, type 1 diabetes, and type 2 diabetes 
by inhibition of excessive iNOS-induced NO release [60], and by other direct glycemic and nonglycemic effects (both metabolic and nonmetabolic) [61]. Insulin's role in improving infection in both clinical and nonclinical studies is also well known $[62,63]$. Insulin can attenuate systematic inflammatory responses and modulate immune functions of monocytes/ macrophages, neutrophils, and $\mathrm{T}$ cells in the setting of sepsis and other disease states [64]. From a physiologic and clinical perspective, there is no reason to believe that insulin should not remain our first therapeutic option for hyperglycemia during the COVID-19 pandemic, provided it can be administered and monitored safely while adequately protecting frontline staff.

There has been discussion about roles of various diabetes medications in COVID-19 disease [65, 66]. Generally, oral medications are not recommended in the inpatient setting, however DPP-IV inhibitors have been considered for more regular use prior to the pandemic. Sulfonylureas/ secretagogues have elevated risk of hypoglycemia, metformin is contraindicated in hypoxia/renal/hepatic dysfunction, SGLT2s increase risk of DKA, and GLPs hold significant risk of nausea/vomiting [67•]. Therefore pragmatically, both DPPIV and insulin have been thought to be best utilized in the inpatient setting prior to and during the pandemic [67•]. In the hospital, prepandemic, DPP-IV inhibitors have been studied in RCTs and have been found to be efficacious and safe [68-70]. Their clinical utility in the hospital in relation to COVID-19 has been considered and in some cases implemented in select patients with mild to moderate hyperglycemia, especially to reduce both workload during a surge as well as exposure for frontline staff caring for patients with COVID19; however, their efficacy and safety in direct comparison to insulin, and in the setting of health care worker (HCW), safety is relatively unknown. Some concern about the use of DPP-IV inhibitors has been raised early on. Specifically, concerns about the known interactions between DPP-IV inhibitors and the immune system have caused hypothetical concern. Older reports have shown an increased incidence of nasopharyngitis and upper respiratory tract infections (URI) associated with the intake of DPP-IV inhibitors in the outpatient settings [71-73]. In addition, DPP-IV, the enzyme targeted by DPPIV inhibitors, is known to be involved in immune regulation [74]. However, there is no evidence of an increased risk of adverse effects associated with DPP-IV use in the setting of SARS-CoV-2 infection. Interestingly, the membrane bound form of DPP-IV acts as a receptor for the MERS variety of coronaviridae [75]. In contrast, COVID-19 targets angiotensin converting enzyme-2 (ACE-2) as a cell entry receptor, and there is no evidence for secondary binding of DPP-IV by SARS-CoV2 [76]. It is unclear what potential immune modulatory effect DPP-IV inhibitors may have on the risk of infection or on altering the course of the exaggerated immune response precipitating ARDS and other complications of
COVID-19. Additionally, whether DPP-IV plays a significant role in lung parenchyma, where DPP-IV is also expressed, in the complex pathophysiologic processes occurring in SARSCoV-2-infected persons is unclear [77, 78]. Overall, the likelihood of a significant effect of DPP-IV inhibitor use on altering the course of a SARS-CoV-2 infection is low. Nevertheless, we suggest that surveillance of data on patients who receive DPP-IV inhibitors during the course of SARSCoV-2 infection should be undertaken. This should also include a careful analysis to help distinguish differences between DPP-IV inhibitors since various DPP-IV inhibitors exhibit different affinities on target half-lives and distribution patterns $[74,79,80]$.

Insulin therefore remains the likely best therapeutic option for patients with COVID-19 with hyperglycemia in the hospital. For those with DKA/severe hyperglycemia/severe insulin resistance, intravenous insulin drips are likely the preferred method of treatment in those with high dose requirements, given its short half-life and ability to titrate quickly. However, it is unknown whether such high amounts of insulin are effective and if and how they affect morbidity and mortality. Hypoglycemia following the sudden resolution of insulin resistance must also be closely examined [31]. There is a need for an increase in monitoring for hypoglycemia as insulin drip rates rise and insulin resistance seemingly resolves. Safety mechanisms will likely need to be put in place should drip rates exceed 20 units $/ \mathrm{h}$. A preemptive decrease in insulin doses may be needed once rates of change show a potential decrease in requirements.

\section{Health Care Worker Safety}

Many workflow changes have been proposed to potentially protect HCW safety. This is a critically important consideration given the frequency of encounters required for blood glucose monitoring and insulin delivery, especially for patients treated with insulin infusions. These intensive regimens require careful consideration in the setting of risk of exposure especially when there may be suboptimal availability of personal protective equipment (PPE) for HCW. Opportunities for treatment modifications that reduce staff face-to-face time with patients with COVID-19 and mitigation of PPE use became critical considerations early on in the USA, especially in the New York City area. The practice of "bundling care," originated years ago by the Institute for Healthcare Improvement, was introduced in hard-hit New York City hospitals (http://www.ihi.org/resources/Pages/ ImprovementStories/WhatIsaBundle.aspx); this approach has been used to reduce other nosocomial infections [81]. During the COVID-19 surge, nurses caring for many patients with COVID-19 would bundle care, along with other interventions, combining as many tasks as possible when entering a patient 
room to conserve both precious time and PPE. In CDC guidance for long-term care facilities during the pandemic, health care professionals were advised to "bundle care" to reduce exposure and PPE use (https://www.cdc.gov/coronavirus/ 2019-ncov/hcp/nursing-homes-responding.html). The CDC also endorsed implementing "contingency strategies" in all US healthcare facilities by modifying some work practices to conserve PPE and staff exposure (https://www.cdc.gov/ coronavirus/2019-ncov/hcp/ppe-strategy/index.html).

The hospital setting, during an outbreak such as SARSCoV-2, can also change dramatically to include novel workflows and engineering of spaces, and in some cases, new providers and team compositions. In addition, use and availability of adequate PPE plays a major factor in protection of HCW. The WHO has issued interim guidance on rational use of PPE for COVID-19, which includes implementation of prevention and mitigation measures and minimizing PPE need, while utilizing PPE appropriately [82]. In addition, current and previous work (2003) in Taiwan has demonstrated decreased nosocomial severe acute respiratory syndrome (SARS) among HCW with implementation of their traffic control bundle (fever screening, separating SARS patients, increasing handwashing stations) [83, 84].

Theoretically, decreasing face-to-face time could be one way to reduce $\mathrm{HCW}$ risk of infection, however this one factor or action cannot be undertaken or understood in isolation. In addition, this strategy does not take into account the increased risk of HCW infection when doffing PPE. Therefore, it would be prudent to try to minimize the frequency of glucose monitoring and insulin administration when possible, if this practice would truly decrease face-to-face time (i.e., nurses were not going into the room otherwise) without significantly compromising patient safety or glycemic outcomes. Bundling blood glucose monitoring, insulin administration, and meal tray delivery would keep within current recommendations while conserving staff exposure and PPE.

Many institutions in the USA have converted some or all of their face-to-face DM consults by endocrinologists, fellows, and diabetes care and education specialists to telehealth encounters, especially in areas with high COVID-19 patient populations [85]. With proper documentation of the visit in time segments, it is hoped that reimbursement will occur. Due to fluctuating guidance on reimbursement based on telehealth services in the USA, this will not be reviewed or taken into account in this document. Electronic glycemic management systems (both algorithm and/or personnel driven) have been shown to be effective for glycemic management in small and large hospital systems and could also be safely implemented [86, 87]. Creative solutions to problems are being shared rapidly across sites, such as off-site clinicians placing orders or supporting new work teams to place insulin or glycemic related orders, to temporary practice changes such as keeping IV pumps outside the ICU hospital rooms so nurses do not have to enter the room to check alarms or adjust rates, and consideration of utilizing continuous glucose monitoring in select patients.

Alternatives to intravenous insulin drips could be considered if needed (if there is a lack of IV pumps, insulin, staffing, and/or need for minimization of face-to-face time), in certain mild to moderate cases of hyperglycemia and/or DKA. In the UK and the USA for example, $\mathrm{q} 4$ hour dosing of rapid acting insulin algorithms have been created (based on weight and/or TDD), along with the addition of long-acting insulin for those with hyperglycemia when an insulin drip is not available [88, 89]. Subcutaneous DKA protocols, with q4 dosing, from prior literature [90] and adapted for COVID-19 (additionally adapted for BMI, steroid use, glucose levels), have also been implemented [88, 89]. In general, such protocols may not be appropriate for those with advanced glycemic disease (severe DKA and/or severe insulin resistance) unless deemed absolutely necessary based on lack of PPE or large patient volumes.

Decisions on modifying existing DM/hyperglycemia protocols should be data driven when at all possible, as clinical care, safety parameters, plans for HCWs (including PPE availability), and COVID-19 case mix likely differ from region to region and institution to institution. Data such as number of patients with COVID-19, POI, regional location of such patients, nursing/care team staffing and workflows, amount and type of PPE available, and burn rate of PPE will all likely factor in on decision-making regarding changes in DM/ hyperglycemia related protocols and workflows.

\section{The Potential Role of Continuous Glucose Monitoring in the COVID-19 Era}

One identified area of potential broadened use of technology in the COVID-19 era has been utilization of continuous glucose monitoring (CGM) in the hospital with the theoretical benefit to decrease face-to-face time. Dexcom and Abbott, at the time of this writing, have issued press releases regarding use of their products in the inpatient setting [91, 92]. To this end, the FDA has recently put out guidance on the potential use of CGM in the hospital (https://www.fda.gov/medicaldevices/blood-glucose-monitoring-devices/faqs-home-useblood-glucose-meters-utilized-within-hospitals-during-covid19-pandemic); the FDA has exercised "enforcement discretion" for hospital use of CGMs during the current pandemic, thereby temporarily sanctioning off label use. Some have interpreted this to mean the FDA has approved CGM use, which is not the case. In addition, CGM studies of hospitalized patients prior to COVID-19 have shown that circumstances commonly occurring in critically ill patients such as dehydration, edema, hypotension, and dialysis may 
negatively impact accuracy because of fluid shifts and changes in perfusion in this population [93]. Because of accuracy concerns, correlation studies should still be performed, and/or correlation protocols between the hospital blood glucose monitor (usual care), and the CGM should be completed to guide safe use.

Case series have been published evaluating the feasibility of remote glucose monitoring and medical management based on CGM data during the pandemic [94-96]. In addition, an RCT interim analysis showed that use of real time CGM via a telemetry system reduces inpatient hypoglycemia in those with type 2 DM on insulin [97], another RCT demonstrated significantly lower mean glucose and increased time in range with the use of real time CGM in the nonICU hospital setting [98*•]. Careful review of the benefits and the barriers to implementation of CGM during this pandemic needs to occur on an institution to institution basis, along with a discussion with quality, safety, and risk teams. Some hospitals have piloted (under research) the use of CGM whereas others concluded that the accuracy limitations and the burden of a novel technology implementation during a pandemic are too great. One main theoretical benefit to remote monitoring is that the nurse can obtain the glucose level outside the room. For patients on an insulin drip, the IV pump could be on a long extension cord also outside the room so that the nurse could view the sensor glucose (SG) on a receiver or phone and adjust the insulin drip rate without additional exposure and use of PPE. Although the Dexcom receiver can transmit up to $20 \mathrm{ft}$, the Freestyle Libre requires scanning close to the sensor. In the case of noncritically ill patients who may not have as many confounding factors related to sensor accuracy compared with critically ill patients, the patient could be an active participant in monitoring SG by scanning the device if applicable (e.g., Libre), viewing the receiver/reader or phone and communicating glucose levels via intercom or phone to the nurse outside the room.

There are many moving parts to planning and implementing CGM use in the inpatient setting during the COVID-19 pandemic. Diabetes specialists should work collaboratively with the hospital's legal team, nursing, medicine, and senior leadership to gain buy-in and approval. Quality improvement frameworks and models, such as the quality implementation framework and the SEIPs (systems engineering model for patient safety) model $[99,100]$ can be utilized to help with planning and implementation. Figure 1 delineates each SEIPs domain as it relates to potential CGM implementation in the hospital setting.

The FDA also recently released "FAQs on Home-Use Blood Glucose Meters Utilized Within Hospitals During the COVID-19 Pandemic." [101]. This document allows patients who are willing and able to use their home BG meters temporarily during the hospital stay. If patients did not bring a $\mathrm{BG}$

Fig. 1 Implementation of CGM during COVID-19

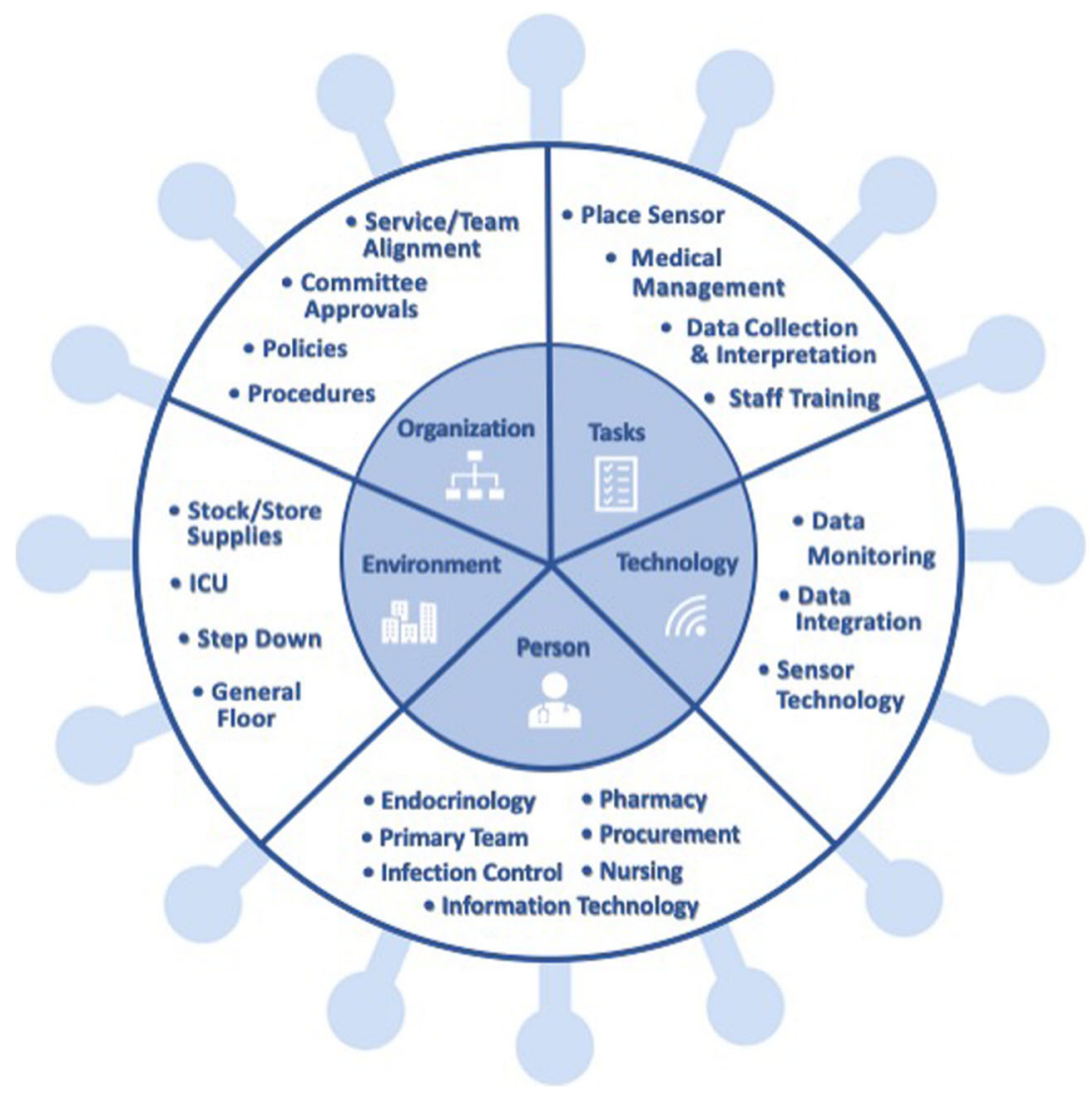


meter, hospitals can also dispense meters that are intended for home use to inpatients. This theoretically reduces the number of BGs nurses need to obtain, thereby reducing risk of exposure and waste of PPE; however, careful consideration of how and when data will be entered into the medical record is needed. All of these changes can result in unintended consequences that have not been identified, so benefits, risks, quality, and safety must be continuously assessed.

\section{Conclusions}

In the end, we must recognize that this global pandemic represents a time when critical decisions must be made quickly, informed by first-hand experience along with evidence-based literature when available. We can resourcefully turn to accepted scientific principles from the past to inform the questions of the present and future. We must work with our institutions and our communities closely, in an unprecedented public-privatenon-profit partnership, to bend the curve on diabetes and COVID-19. We may need to harness and modify our existing institutional frameworks to safely meet the needs of our patients while protecting the welfare and safety of $\mathrm{HCW}$ during this unprecedented crisis. This is the time to share data and information faster and more generously than ever before to most efficiently gain an understanding of disease pathophysiology and best practice. Most of all, we must ensure that we maintain guidance by the ethos to "do no harm," but do everything we can to prepare for any potential resurgence of this disease.

\section{Compliance with Ethical Standards}

Conflict of Interest Amisha Wallia is a section editor for Current Diabetes Reports and recieves grant funding from Novo Nordisk, and research salary support from United Health Group and Eli Lilly. Grace Prince, Emilie Touma, and Malek El Muayed each declare no potential conflicts of interest. Jane Jeffrie Seley is a section editor for Current Diabetes Reports.

Human and Animal Rights and Informed Consent This article does not contain any studies with human or animal subjects performed by any of the authors.

\section{References}

Papers of particular interest, published recently, have been highlighted as:

- Of importance

•- Of major importance

1. Coronavirus COVID-19 Global Cases by the Center for Systems Science and Engineering (CSSE) at Johns Hopkins University. 2020. at https://systems.jhu.edu/research/public-health/ncov/.)
2. Garg S KL, Whitaker M, et al. Hospitalization Rates and Characteristics of Patients Hospitalized with LaboratoryConfirmed Coronavirus Disease 2019 - COVID-NET, 14 States, March 1-30, 2020 US Department of Health and Human Services/Centers for Disease Control and Prevention; April 17, 2020.

3. Muniyappa R, Gubbi S. COVID-19 pandemic, coronaviruses, and diabetes mellitus. Am J Phys Endocrinol Metab. 2020;318:E736e41.

4. Yang JK, Feng Y, Yuan MY, Yuan SY, Fu HJ, Wu BY, et al. Plasma glucose levels and diabetes are independent predictors for mortality and morbidity in patients with SARS. Diabet Med. 2006;23:623-8.

5. Abstract No 2039-PO. 64th American Diabetes Association Scientific Sessions2004.

6. Apicella M, Campopiano MC, Mantuano M, Mazoni L, Coppelli A, Del Prato S. COVID-19 in people with diabetes: understanding the reasons for worse outcomes. Lancet Diabetes Endocrinol. 2020;8:782-92.

7.• Holman N, Knighton P, Kar P, et al. Risk factors for COVID-19related mortality in people with type 1 and type 2 diabetes in England: a population-based cohort study. Lancet Diabetes Endocrinol. 2020. This is a population based cohort study of people with diagnosed diabetes in England.

8. Wu C, Chen X, Cai Y, et al. Risk factors associated with acute respiratory distress syndrome and death in patients with coronavirus disease 2019 Pneumonia in Wuhan, China. JAMA Intern Med. 2020;180:1.

9. Report of the WHO-China Joint Mission on Coronavirus Disease 2019 (COVID-19). Feb 16, 2020.

10. Coronavirus disease 2019 (COVID-19) pandemic: increased transmission in the EU/EEA and the UK - seventh update, 2020. Stockholm: ECDC; 2020.

11. Bode B, Garrett V, Messler J, et al. Glycemic characteristics and clinical outcomes of COVID-19 patients hospitalized in the United States. J Diabetes Sci Technol. 2020;14:813 1932296820924469.

12. Petrilli CM, Jones SA, Yang J, Rajagopalan H, O'Donnell L, Chernyak Y, et al. Factors associated with hospitalization and critical illness among 5279 people with coronavirus disease 2019 in New York City: prospective cohort study. BMJ. 2020;369:m1966.

13. Simonnet A, Chetboun M, Poissy J, Raverdy V, Noulette J, Duhamel A, et al. High prevalence of obesity in severe acute respiratory syndrome coronavirus-2 (SARS-CoV-2) requiring invasive mechanical ventilation. Obesity (Silver Spring). 2020;28: 1195-9.

14. Tartof SY, Qian L, Hong V, Wei R, Nadjafi RF, Fischer H, Li Z, Shaw SF, Caparosa SL, Nau CL, Saxena T, Rieg GK, Ackerson BK, Sharp AL, Skarbinski J, Naik TK, Murali SB Obesity and mortality among patients diagnosed with COVID-19: results from an integrated health care organization. Ann Intern Med 2020.

15. Bode B, Garrett V, Messler J, McFarland R, Crowe J, Booth R, et al. Glycemic characteristics and clinical outcomes of COVID-19 patients hospitalized in the United States. J Diabetes Sci Technol. 2020;14(4):813-21.

16. Zhu L, She ZG, Cheng X, Qin JJ, Zhang XJ, Cai J, et al. Association of blood glucose control and outcomes in patients with COVID-19 and pre-existing type 2 diabetes. Cell Metab. 2020;31:1068-1077.e3.

17. Cariou B, Hadjadj S, Wargny M, et al. Phenotypic characteristics and prognosis of inpatients with COVID-19 and diabetes: the CORONADO study. Diabetologia. 2020;63:1500-15.

18. Agarwal S, Schechter C, Southern W, Crandall JP, Tomer Y. Preadmission diabetes-specific risk factors for mortality in 
hospitalized patients with diabetes and coronavirus disease. Diabetes Care. 2019;43:2020.

19. Chen Y, Yang D, Cheng B, Chen J, Peng A, Yang C, et al. Clinical characteristics and outcomes of patients with diabetes and COVID-19 in association with glucose-lowering medication. Diabetes Care. 2020;43:1399-407.

20. Wang S, Ma P, Zhang S, Song S, Wang Z, Ma Y, et al. Fasting blood glucose at admission is an independent predictor for 28-day mortality in patients with COVID-19 without previous diagnosis of diabetes: a multi-centre retrospective study. Diabetologia. 2020;63:2102-11.

21. Kim NYHE, Moon JS, Lee YH, C EU. Acute hyperglycemic crises with coronavirus disease-19: case reports. Diabetes Metab J. 2020;44:349-53.

22. Jie Chee Y, Jia Huey Ng S, Yeoh E. Diabetic ketoacidosis precipitated by Covid-19 in a patient with newly diagnosed diabetes mellitus. Diabetes Res Clin Pract 2020:108166, 164.

23. Palermo NE, Sadhu AR, McDonnell ME. Diabetic ketoacidosis in COVID-19: unique concerns and considerations. J Clin Endocrinol Metab. 2020;105:2819-29.

24. Bornstein SR, Rubino F, Khunti K, et al. Practical recommendations for the management of diabetes in patients with COVID-19. Lancet Diabetes Endocrinol. 2020;8:546.

25. Pal R, Banerjee M, Yadav U, Bhattacharjee S. Clinical profile and outcomes in COVID-19 patients with diabetic ketoacidosis: a systematic review of literature. Diabetes Metab Syndr. 2020;14: 1563-9.

26. Gianchandani R, Esfandiari NH, Ang L, Iyengar J, Knotts S, Choksi P, et al. Managing hyperglycemia in the COVID-19 inflammatory storm. Diabetes. 2020;69:2048-53.

27. Le Roith D, et al. Diabetes mellitus: a fundamental and clinical text. 3rd ed. Philadelphia: Lippincott Williams \& Wilkins; 2003.

28. Ovalle F. Clinical approach to the patient with diabetes mellitus and very high insulin requirements. Diabetes Res Clin Pract. 2010;90:231-42.

29. Illuri VD, Layden BT, Aleppo G. Extreme insulin resistance in critically ill patient with sepsis. Clin Diabetes. 2016;34:158-60.

30. Ettleson MD, Arguello V, Wallia A, Arguelles L, Bernstein RA, Molitch ME. Hyperglycemia and insulin resistance in cardiac arrest patients treated with moderate hypothermia. J Clin Endocrinol Metab. 2014;99:E2010-4.

31. Gupta S, Johnson Oakes D, Therasse A, Wallia A, Molitch ME. Extreme insulin resistance following heart transplant. In: Draznin B, editor. Diabetes case studies: real problems, practical solutions. Alexandria: American Diabetes Association; 2015. p. 214-7.

32. Oo YH, Karam JG, Resta CA. Extreme insulin resistance in a patient with diabetes ketoacidosis and acute myocardial infarction. Case Rep Endocrinol. 2013;2013:520904.

33. Donath MY, Storling J, Berchtold LA, Billestrup N, MandrupPoulsen T. Cytokines and beta-cell biology: from concept to clinical translation. Endocr Rev. 2008;29:334-50.

34. Pilla SJ, Quan AQ, Germain-Lee EL, Hellmann DB, Mathioudakis NN. Immune-modulating therapy for rheumatologic disease: implications for patients with diabetes. Curr Diab Rep. 2016;16:91.

35. Winter EM, Schrander-van der Meer A, Eustatia-Rutten C, Janssen M. Hydroxychloroquine as a glucose lowering drug. BMJ Case Rep. 2011;bcr0620114393.

36. Filippi CM, von Herrath MG. Viral trigger for type 1 diabetes: pros and cons. Diabetes. 2008;57:2863-71.

37. Hyoty H, Taylor KW. The role of viruses in human diabetes. Diabetologia. 2002;45:1353-61.

38. Roivainen M. Enteroviruses: new findings on the role of enteroviruses in type 1 diabetes. Int J Biochem Cell Biol. 2006;38:7215 .

39. Honeyman MC, Stone NL, Harrison LC. T-cell epitopes in type 1 diabetes autoantigen tyrosine phosphatase IA-2: potential for mimicry with rotavirus and other environmental agents. Mol Med. 1998;4:231-9.

40. Honeyman MC, Coulson BS, Stone NL, Gellert SA, Goldwater $\mathrm{PN}$, Steele CE, et al. Association between rotavirus infection and pancreatic islet autoimmunity in children at risk of developing type 1 diabetes. Diabetes. 2000;49:1319-24.

41. Sjoholm A. Ketosis-prone type 2 diabetes: a case series. Front Endocrinol. 2019;10:684.

42. Balasubramanyam A, Nalini R, Hampe CS, Maldonado M. Syndromes of ketosis-prone diabetes mellitus. Endocr Rev. 2008;29:292-302.

43. Yang JK, Lin SS, Ji XJ, Guo LM. Binding of SARS coronavirus to its receptor damages islets and causes acute diabetes. Acta Diabetol. 2010;47:193-9.

44. Liu F, Long X, Zhang B, Zhang W, Chen X, Zhang Z. ACE2 expression in pancreas may cause pancreatic damage after SARS-CoV-2 infection. Clin Gastroenterol Hepatol. 2020;18: 2128-2130.e2.

45. Tikellis C, Wookey PJ, Candido R, Andrikopoulos S, Thomas $\mathrm{MC}$, Cooper ME. Improved islet morphology after blockade of the renin- angiotensin system in the ZDF rat. Diabetes. 2004;53: 989-97.

46. Hoffmann M, Kleine-Weber H, Schroeder S, et al. SARS-CoV-2 cell entry depends on ACE2 and TMPRSS2 and is blocked by a clinically proven protease inhibitor. Cell. 2020;181:271-80.e8.

47. Huang C, Wang Y, Li X, Ren L, Zhao J, Hu Y, et al. Clinical features of patients infected with 2019 novel coronavirus in Wuhan, China. Lancet. 2020;395:497-506.

48. Young BE, Ong SWX, Kalimuddin S, Low JG, Tan SY, Loh J, et al. Epidemiologic features and clinical course of patients infected with SARS-CoV-2 in Singapore. Jama. 2020;323:1488-94.

49. Lecube A, Hernandez C, Genesca J, Simo R. Glucose abnormalities in patients with hepatitis $\mathrm{C}$ virus infection: epidemiology and pathogenesis. Diabetes Care. 2006;29:1140-9.

50. Venetsanaki V, Boutis A, Chrisoulidou A, Papakotoulas P. Diabetes mellitus secondary to treatment with immune checkpoint inhibitors. Curr Oncol. 2019;26:e111-e4.

51. Uhteg K, Jarrett J, Richards M, Howard C, Morehead E, Geahr M, et al. Comparing the analytical performance of three SARS-CoV2 molecular diagnostic assays. J Clin Virol. 2020;127:104384.

52. Ai T, Yang Z, Hou H, et al. Correlation of chest CT and RT-PCR testing in coronavirus disease 2019 (COVID-19) in China: a report of 1014 cases. Radiology. 2020;296(2):E32-40.

53. Hanson K, Caliendo A, Arias C, Englund J, Lee M, Loeb M, et al. Infectious Disease Society of America Guidelines on the Diagnosis of COVID-19. Clin Infect Dis. 2020; ciaa760.

54. EUA Authorized Serology Test Performance U.S. Food \& Drug Administration 2020. at https://www.fda.gov/medical-devices/ emergency-situations-medical-devices/eua-authorized-serologytest-performance.)

55. Sardu C, D'Onofrio N, Balestrieri ML, et al. Outcomes in patients with hyperglycemia affected by COVID-19: can we do more on glycemic control? Diabetes Care. 2020;43:1408-15.

56. 15. Diabetes Care in the Hospital: Standards of Medical Care in Diabetes-2020. Diabetes Care. 2020;43(Suppl 1):S193-202.

57. Van den Berghe G, Wilmer A, Hermans G, et al. Intensive insulin therapy in the medical ICU. N Engl J Med. 2006;354:449-61.

58. van den Berghe G, Wouters P, Weekers F, Verwaest C, Bruyninckx F, Schetz M, et al. Intensive insulin therapy in critically ill patients. N Engl J Med. 2001;345:1359-67.

59. Kumar S, Molitch ME. Use of insulin in the inpatient setting: need for continued use. Curr Diab Rep. 2019;19:64.

60. Langouche L, Vanhorebeek I, Vlasselaers D, Vander Perre S, Wouters PJ, Skogstrand K, et al. Intensive insulin therapy protects the endothelium of critically ill patients. J Clin Invest. 2005;115: 2277-86. 
61. Vanhorebeek I, Langouche L, Van den Berghe G. Glycemic and nonglycemic effects of insulin: how do they contribute to a better outcome of critical illness? Curr Opin Crit Care. 2005;11:304-11.

62. Wallia A, Schmidt K, Johnson Oakes D, Pollack T, Welsh N, Kling-Colson S, et al. Glycemic control reduces infections in post-liver transplant patients: results of a prospective, randomized study. J Clin Endocrinol Metab. 2017;102(2):451-9.

63. Andersen SK, Gjedsted J, Christiansen C, Tonnesen E. The roles of insulin and hyperglycemia in sepsis pathogenesis. J Leukoc Biol. 2004;75:413-21.

64. Deng HP, Chai JK. The effects and mechanisms of insulin on systemic inflammatory response and immune cells in severe trauma, burn injury, and sepsis. Int Immunopharmacol. 2009;9:12519 .

65. Iacobellis G. COVID-19 and diabetes: can DPP4 inhibition play a role? Diabetes Res Clin Pract. 2020;162:108125.

66. Drucker DJ. Coronavirus infections and type 2 diabetes-shared pathways with therapeutic implications. Endocr Rev. 2020;41.

67. Korytkowski M, Antinori-Lent K, Drincic A, Hirsch I, McDonnell $\mathrm{M}$, Rushakoff R, et al. A pragmatic approach to inpatient diabetes management during the COVID-19 pandemic. J Clin Endocrinol Metab. 2020;105(9):dgaa342. This is a practical review article on management of those inpatient with hyperglycemia and COVID-19.

68. Vellanki P, Rasouli N, Baldwin D, Alexanian S, Anzola I, Urrutia $\mathrm{M}$, et al. Glycaemic efficacy and safety of linagliptin compared to a basal-bolus insulin regimen in patients with type 2 diabetes undergoing non-cardiac surgery: a multicentre randomized clinical trial. Diabetes Obes Metab. 2019;21:837-43.

69. Pasquel FJ, Fayfman M, Umpierrez GE. Debate on insulin vs noninsulin use in the hospital setting-is it time to revise the guidelines for the management of inpatient diabetes? Curr Diab Rep. 2019;19:65.

70. Lorenzo-Gonzalez C, Atienza-Sanchez E, Reyes-Umpierrez D, et al. Safety and efficacy of ddp4-inhibitors for management of hospitalized general medicine and surgery patients with type 2 diabetes. Endocrine Pract. 2020;26:722-8.

71. Amori RE, Lau J, Pittas AG. Efficacy and safety of incretin therapy in type 2 diabetes: systematic review and meta-analysis. Jama. 2007;298:194-206.

72. Mikhail N. Safety of dipeptidyl peptidase 4 inhibitors for treatment of type 2 diabetes. Curr Drug Saf. 2011;6:304-9.

73. Willemen MJ, Mantel-Teeuwisse AK, Straus SM, Meyboom RH, Egberts TC, Leufkens HG. Use of dipeptidyl peptidase-4 inhibitors and the reporting of infections: a disproportionality analysis in the World Health Organization VigiBase. Diabetes Care. 2011;34: 369-74.

74. Mulvihill EE, Drucker DJ. Pharmacology, physiology, and mechanisms of action of dipeptidyl peptidase-4 inhibitors. Endocr Rev. 2014;35:992-1019.

75. Raj VS, Mou H, Smits SL, Dekkers DHW, Müller MA, Dijkman $\mathrm{R}$, et al. Dipeptidyl peptidase 4 is a functional receptor for the emerging human coronavirus-EMC. Nature. 2013;495:251-4.

76. Tai W, He L, Zhang X, Pu J, Voronin D, Jiang S, et al. Characterization of the receptor-binding domain (RBD) of 2019 novel coronavirus: implication for development of RBD protein as a viral attachment inhibitor and vaccine. Cell Mol Immunol. 2020;17:613-20.

77. Xu J, Wang J, He M, Han H, Xie W, Wang H, et al. Dipeptidyl peptidase IV (DPP-4) inhibition alleviates pulmonary arterial remodeling in experimental pulmonary hypertension. Lab Investig. 2018;98:1333-46.

78. Meyerholz DK, Lambertz AM, McCray PB Jr. Dipeptidyl peptidase 4 distribution in the human respiratory tract: implications for the Middle East respiratory syndrome. Am J Pathol. 2016;186:78 86.
79. Schnapp G, Klein T, Hoevels Y, Bakker RA, Nar H. Comparative analysis of binding kinetics and thermodynamics of dipeptidyl peptidase- 4 inhibitors and their relationship to structure. J Med Chem. 2016;59:7466-77.

80. Reichetzeder C, von Websky K, Tsuprykov O, Mohagheghi Samarin A, Falke LG, Dwi Putra SE, et al. Head-to-head comparison of structurally unrelated dipeptidyl peptidase 4 inhibitors in the setting of renal ischemia reperfusion injury. Br J Pharmacol. 2017;174:2273-86.

81. Resar R, Pronovost P, Haraden C, Simmonds T, Rainey T, Nolan $\mathrm{T}$. Using a bundle approach to improve ventilator care processes and reduce ventilator-associated pneumonia. Jt Comm J Qual Patient Saf. 2005;31:243-8.

82. World Health Organization. Rational use of personal protective equipment (PPE) for coronavirus disease (COVID-19): interim guidance, 19 March 2020. World Health Organization; 2020. https://apps.who.int/iris/handle/10665/331498.

83. Schwartz J, King CC, Yen MY. Protecting health care workers during the COVID-19 coronavirus outbreak -lessons from Taiwan's SARS response. Clin Infect Dis. 2020;53:363.

84. Yen MY, Lin YE, Lee CH, Ho MS, Huang FY, Chang SC, et al. Taiwan's traffic control bundle and the elimination of nosocomial severe acute respiratory syndrome among healthcare workers. J Hospital Infection. 2011;77:332-7.

85. Jones MS, Goley AL, Alexander BE, Keller SB, Caldwell MM, Buse JB. Inpatient transition to virtual care during COVID-19 pandemic. Diabetes Technol Ther. 2020;22:444-8.

86. Rushakoff RJ, Sullivan MM, MacMaster HW, et al. Association between a virtual glucose management service and glycemic control in hospitalized adult patients: an observational study. Ann Intern Med. 2017;166:621-7.

87. Aloi J, Bode BW, Ullal J, Chidester P, McFarland RS, Bedingfield $\mathrm{AE}$, et al. Comparison of an electronic glycemic management system versus provider-managed subcutaneous basal bolus insulin therapy in the hospital setting. J Diabetes Sci Technol. 2017;11: $12-6$.

88. Inpatient Insulin Protocols - COVID-19. American Diabetes Association at https://professional.diabetes.org/content-page/ inpatient-insulin-protocols-covid-19.)

89. COVID In Diabetes: Collaborative Open-access VIrtual Database for COVID-19 in Diabetes. at https://www.covidindiabetes.org.)

90. Umpierrez GE, Cuervo R, Karabell A, Latif K, Freire AX, Kitabchi AE. Treatment of diabetic ketoacidosis with subcutaneous insulin aspart. Diabetes Care. 2004;27:1873-8.

91. Abbott's Freestyle Libre 14 day system now available in US for hospitalized patients with diabetes during COVID-19 pandemic. Abbott; 2020.

92. Fact sheet for healthcare providers: use of dexcom continuous glucose monitoring systems during the COVID-19 pandemic. Dexcom 2020.

93. Wallia A, Umpierrez GE, Rushakoff RJ, Klonoff DC, Rubin DJ, Hill Golden S, et al. Consensus statement on inpatient use of continuous glucose monitoring. J Diabetes Sci Technol. 2017;11:1036-44.

94. Shehav-Zaltzman G, Segal G, Konvalina N, Tirosh A. Remote glucose monitoring of hospitalized, quarantined patients with diabetes and COVID-19. Diabetes Care. 2020;43:e75-e6.

95. Ushigome E, Yamazaki M, Hamaguchi M, Ito T, Matsubara S, Tsuchido Y, et al. Usefulness and safety of remote continuous glucose monitoring for a severe COVID-19 patient with diabetes. Diabetes Technol Ther. 2020.

96. Reutrakul S, Genco M, Salinas H, et al. Feasibility of inpatient continuous glucose monitoring during the COVID-19 pandemic: early experience. Diabetes Care. 2020.

97. Singh LG, Satyarengga M, Marcano I, Scott WH, Pinault LF, Feng $\mathrm{Z}$, et al. Reducing inpatient hypoglycemia in the general 
wards using real-time continuous glucose monitoring: the glucose telemetry system, a randomized clinical trial. Diabetes Care. 2020;43:2736-43.

98.• Fortmann AL, Spierling Bagsic SR, Talavera L, et al. Glucose as the fifth vital sign: a randomized controlled trial of continuous glucose monitoring in a non-ICU hospital setting. Diabetes Care. 2020;43:2873. This is a randomized controlled trial of realtime continuous glucose monitoring compared to point of care in a non-ICU community hospital setting.

99. Carayon P, Schoofs Hundt A, Karsh BT, Gurses AP, Alvarado CJ, Smith M, et al. Work system design for patient safety: the SEIPS model. Qual Saf Health Care. 2006;15(Suppl 1):i50-i8.

100. Meyers DC, Durlak JA, Wandersman A. The quality implementation framework: a synthesis of critical steps in the implementation process. Am J Community Psychol. 2012;50:462-80.

101. FAQs on home-use blood glucose meters utilized within hospitals during the COVID-19 pandemic. U.S. Food \& Drug Administration 2020. at https://www.fda.gov/medical-devices/ blood-glucose-monitoring-devices/faqs-home-use-blood-glucosemeters-utilized-within-hospitals-during-covid-19-pandemic.)

102. Hoffman T, Nissen K, Krambrich J. Evaluation of a COVID-19 $\mathrm{IgM}$ and $\mathrm{IgG}$ rapid test; an efficient tool for assessment of past exposure to SARS-CoV-2. 2020;10:1754538.

103. Esposito K, Nappo F, Marfella R, Giugliano G, Giugliano F, Ciotola $\mathrm{M}$, et al. Inflammatory cytokine concentrations are acutely increased by hyperglycemia in humans: role of oxidative stress. Circulation. 2002;106:2067-72.

104. Dungan KM, Braithwaite SS, Preiser JC. Stress hyperglycaemia. Lancet. 2009;373:1798-807.

105. Wang XL, Zhang L, Youker K, Zhang MX, Wang J, LeMaire SA, et al. Free fatty acids inhibit insulin signaling-stimulated endothelial nitric oxide synthase activation through upregulating PTEN or inhibiting Akt kinase. Diabetes. 2006;55:2301-10.
106. Stefan N, Birkenfeld AL, Schulze MB, Ludwig DS. Obesity and impaired metabolic health in patients with COVID-19. Nat Rev Endocrinol. 2020;16:341-2.

107. Ansorge S, Bank U, Heimburg A, et al. Recent insights into the role of dipeptidyl aminopeptidase IV (DPIV) and aminopeptidase $\mathrm{N}$ (APN) families in immune functions. Clin Chem Lab Med. 2009;47:253-61.

108. Atkinson MA, Eisenbarth GS, Michels AW. Type 1 diabetes. Lancet. 2014;383:69-82.

109. Noble JA, Valdes AM. Genetics of the HLA region in the prediction of type 1 diabetes. Curr Diab Rep. 2011;11:533-42.

110. DiMeglio LA, Evans-Molina C, Oram RA. Type 1 diabetes. Lancet. 2018;391:2449-62.

111. Lehmann-Werman R, Neiman D, Zemmour H, Moss J, Magenheim J, Vaknin-Dembinsky A, et al. Identification of tissue-specific cell death using methylation patterns of circulating DNA. Proc Natl Acad Sci U S A. 2016;113:E1826-34.

112. Gala-Lopez BL, Neiman D, Kin T, et al. Beta cell death by cellfree DNA and outcome after clinical islet transplantation. Transplantation. 2018;102:978-85.

113. Tersey SA, Nelson JB, Fisher MM, Mirmira RG. Measurement of differentially methylated INS DNA species in human serum samples as a biomarker of islet beta cell death. J Vis Exp. 2016;(118): 54838. https://doi.org/10.3791/54838.

114. Naylor R, Knight Johnson A, del Gaudio D. Maturity-onset diabetes of the young overview. In: Adam MP, Ardinger HH, Pagon RA, et al., editors. GeneReviews((R)). Seattle: University of Washington, Seattle. University of Washington, Seattle. GeneReviews is a registered trademark of the University of Washington, Seattle. All rights reserved; 1993.

Publisher's Note Springer Nature remains neutral with regard to jurisdictional claims in published maps and institutional affiliations. 